\title{
Application of radar techniques to the verification of design plans and the detection of defects in concrete bridges
}

\author{
Paulo J.S. Cruz ${ }^{\mathrm{a} *}$, Lukasz Topczewski ${ }^{\mathrm{a}}$, Francisco M. Fernandes ${ }^{\mathrm{a}}$, Christiane Trela ${ }^{\mathrm{b}}$ and \\ Paulo B. Lourenço ${ }^{\mathrm{a}}$ \\ ${ }^{a}$ Department of Civil Engineering, University of Minho, Guimarães, Portugal; ${ }^{b}$ Federal Institute for Materials Research and Testing \\ (BAM), Berlin, Germany
}

(Received 11 December 2006; final version received 31 October 2007)

\begin{abstract}
Non-destructive tests (NDT) are an essential tool used in special inspections to gather detailed information about the condition of a bridge. The inspection of bridge decks is a critical task, and, currently, can be successfully carried out using a wide range of NDT techniques. Nevertheless, some of these techniques are excessively expensive and time consuming. One of these techniques, the ground penetrating radar (GPR), has been used for some decades in the non-destructive inspection and diagnosis of concrete bridges. GPR is useful to find general information about the true position of reinforcement and tendon ducts, and check the quality of the construction and materials. A significant number of reinforced and prestressed concrete bridges are deteriorating at a rapid rate and need to be repaired and strengthened. During these rehabilitation processes, designers are often faced with a lack of original design plans and unawareness of the real position of reinforcement and tendon ducts. In this paper, three case studies of the use of GPR techniques for the inspection of concrete bridges are presented and analysed. The main aim of this research is to show the strong need and usefulness of these techniques, which can provide non-visible information about structural geometry and integrity required for strengthening and rehabilitation purposes.
\end{abstract}

Keywords: non-destructive tests; ground penetrating radar; tomography; bridge condition assessment; detection of defects

\section{Introduction}

In the last few decades, the number of bridges has increased considerably due to the significant expansion of the road and railway networks. Nowadays, some of those structures show a varied range of defects. Nevertheless, the safety and the functionality of those bridges must be guaranteed by condition and safety assessments followed by adequate maintenance and rehabilitation actions, which require gathering an extensive amount of data related to the bridge characteristics and condition. In this context, nondestructive testing (NDT) techniques are becoming increasingly popular and indispensable to collect reliable and valuable information.

In the particular case of prestressed concrete bridges, which is addressed in this paper, the location of the tendon ducts and ordinary reinforcement is fundamental in rehabilitation work. In addition, the verification of the quality of work during its execution and initial life is absolutely necessary in order to prevent the occurrence of early deterioration such as reinforcement corrosion. Ground penetrating radar
(GPR) is one of the leading techniques especially prepared for these purposes (Daniels 2004).

Nowadays, GPR systems are increasingly being used as a diagnostic and quality assurance tool for concrete structures (Maierhofer and Kind 2002). The use of this tool has been validated by numerous authors for the assessment of the metallic reinforcement bars (e.g. Dérobert et al. 2002, Maierhofer et al. 2003 ), in the inspection of grouting quality inside plastic tendon ducts (e.g. Giannopolous et al. 2002, Forde 2004), and in the diagnosis of defects in concrete structures (e.g. Taffe et al. 2003).

The inspection of bridge decks, particularly in the case of prestressed concrete bridges, is a critical task, but has been successfully carried out by many researchers (e.g. Hugenschmidt 2002, Scott et al. 2003). GPR is progressively replacing other techniques, such as radiographies, as it is usually considered faster and safer to apply. Generally, radioactive methods require special certified operators and the closure of an extended perimeter around the test location for security and health purposes (Mitchell 2004).

\footnotetext{
*Corresponding author. Email: pcruz@civil.uminho.pt 
In this research, GPR inspections were carried out in three large concrete bridges located in the northern part of Portugal. These applications clearly illustrate the potential to obtain the information necessary for strengthening design, namely, to locate the exact position of tendon ducts and reinforcement. In one of these examples, the application of tomographic techniques made assessment of the concrete quality and comparison with the information obtained with sensors installed inside these elements possible.

\section{Description of the GPR technique}

\subsection{Reflection measurements}

The most usual way of performing GPR surveys is by collecting the echoes of hidden features. In this way, a GPR system sends electromagnetic radiation pulses into the investigation area through a transmitting antenna. The electromagnetic wave generated is partially reflected by changes in bulk electrical properties of the features or objects encountered by the radiowave and the reflection is picked up by the receiving antenna. The general description of this methodology is illustrated in Figure 1, where twodimensional (2D) radargrams (bottom) were obtained
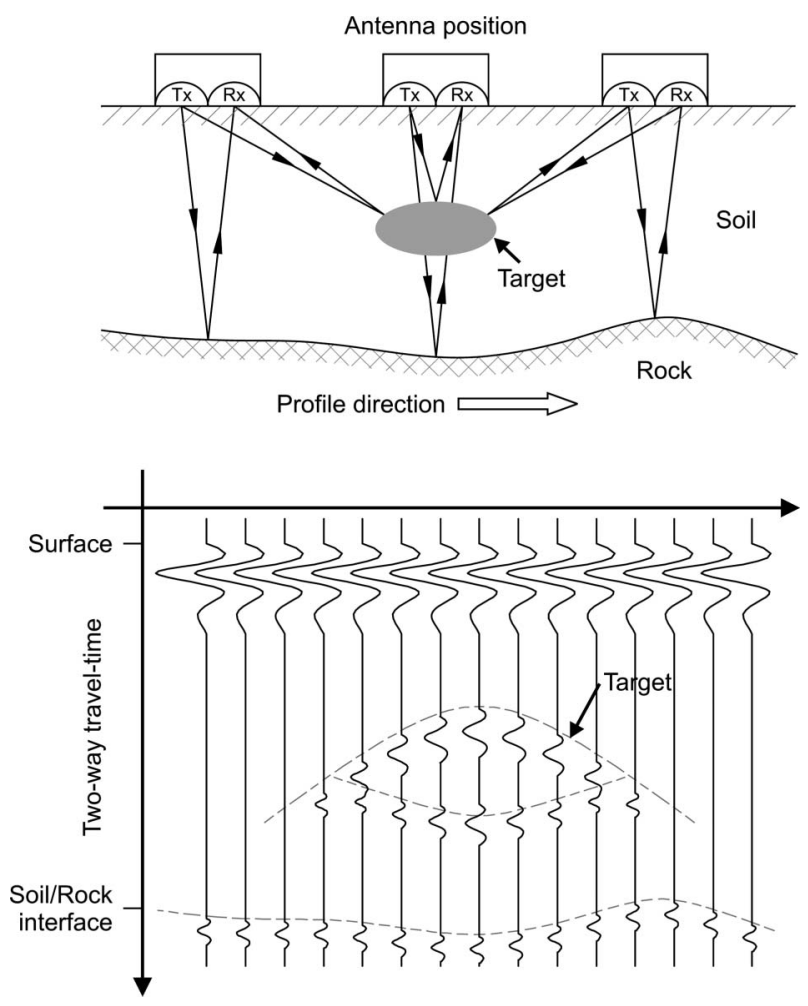

Figure 1. General methodology for GPR field acquisition in reflection mode (top), and 2D radargram (B-scan) as a result (bottom). by plotting successive individual traces (designated by A-scans). These time series contain the amplitude of electromagnetic waves.

Most interesting anomalies for bridge inspection are oriented perpendicularly to the investigation axis and are detected as diffraction hyperbolae. Typically, this includes reinforcement bars, water pipes, tendon ducts, etc. After field acquisition, the raw data is processed using special software, where different filters and focusing algorithms are applied to the dataset to enhance detected features (Valle et al. 2000). Data can also be visualised as a three-dimensional (3D) volume by interpolating several parallel 2D profiles, as illustrated in Figure 2.

\subsection{Transmission or tomography measurements}

Radar tomography is a recent technique to map the interior of objects such as columns or slabs. The general methodology consists of placing two antennas on opposite surfaces (see Figure 3) and sending an electromagnetic pulse from one antenna (transmitter) to a second antenna (receiver). The information from the travel time or the amplitude from many transmitter-receiver pairs is then used to reconstruct the hidden

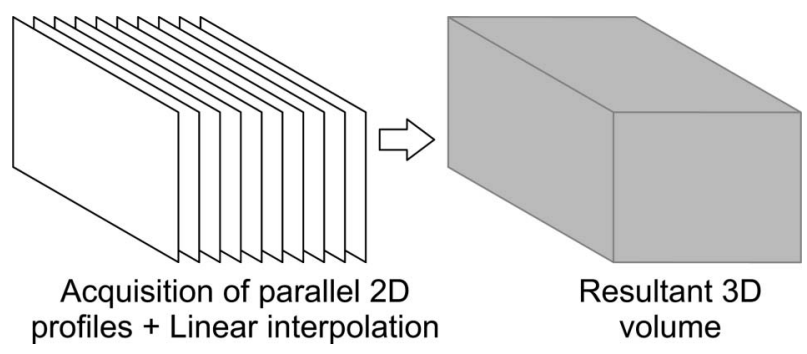

Figure 2. General methodology for producing 3D volumes from field data acquired in reflection mode.

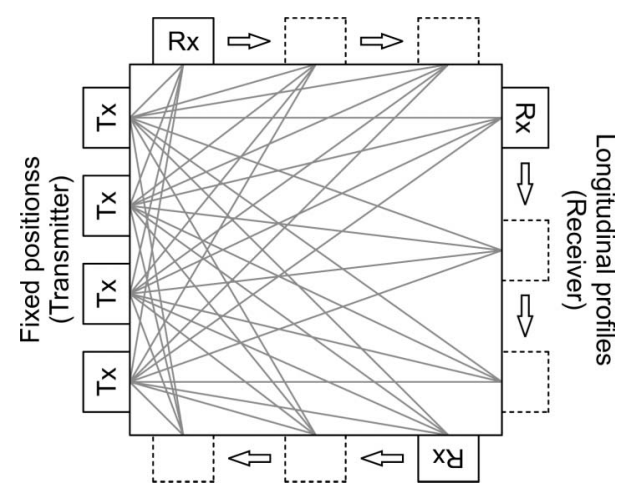

Figure 3. Tomography applied to a square column showing the distribution of transmitters and receivers. 
structure through the use of special inversion algorithms. In general terms, the radar velocity tomography technique has already been successfully applied to the inspection of masonry structures (Binda et al. 2003, Topczewski et al. 2006). In concrete, tomographic research has been primarily based on acoustic waves (Olson 2004), while the radar technique has not previously been reported according to our knowledge.

After the processing steps described, the final image must be interpreted. In the case where electromagnetic waves penetrate through concrete structures, the higher velocities usually correspond to the presence of air voids (or cracks) or areas with very poorly compacted concrete. Areas with low velocities might indicate the presence of moisture, which significantly slows down the velocity. During the inversion process, inversion artefacts are almost always produced. They must be identified and eliminated, if possible, from the final image. Due to the complexity of the inversion process and of the interpretation procedures, only skilled operators are able to process and interpret tomographic data. Additional information about the technique and reconstruction algorithms can be found elsewhere (e.g. Buyukozturk 1998, Valle et al. 1999, Tronicke et al. 2002, Becht et al. 2004).

\section{Main characteristics of the inspected bridges}

\subsection{Lanheses Bridge}

The Lanheses Bridge, which crosses the Lima River, was designed by the famous Portuguese bridge engineer, Edgar Cardoso, in the 1970s and was built in 1981. Currently, it suffers from significant deterioration after more than 30 years of service life.

The Lanheses Bridge is illustrated in Figure 4. It is a cantilever bridge with a total length of $1218 \mathrm{~m}$ between abutments and the width of the bridge deck is $11.5 \mathrm{~m}$. The superstructure, in reinforced and prestressed concrete, consists of four longitudinal beams with variable inertia, connected superiorly by the deck's slab and transversally by beams located over the columns and at thirds of the spans. The bridge presents, along its length, typical spans of $30.0 \mathrm{~m}$, with the exception of the approach spans, which have a length of $24.0 \mathrm{~m}$.

The columns, in reinforced concrete, have a large slenderness, a rectangular cross-section, and are rounded at the extremities. They are articulated at the top and at the base, which allows a pendulum movement that does not resist any horizontal force. The abutments consist of walls in harmonium and extend for $10.3 \mathrm{~m}$. The complete bridge deck works as a cantilever deck, which is fixed at the south margin of the river and is free at the north margin. The supports of the column extremities are ball-and-socket joints, with lead plates and bolts. In the north margin, the mobile extremity of the bridge deck is made with pinned steel bearings.

\subsection{Barra Bridge}

The Barra Bridge, which crosses the delta of the Vouga River ('Ria de Aveiro'), in Ílhavo, was also designed by Edgar Cardoso in 1972 and was built in 1978. Currently, this bridge suffers from significant deterioration caused by contact with seawater, an aggressive environment and nearly 30 years of service-life. Figure 5 illustrates a general view of the structure. The total length of the bridge is about $620 \mathrm{~m}$ between the abutments, and the width of the bridge deck is $15.9 \mathrm{~m}$. The bridge deck is composed of reinforced concrete that is supported by four longitudinal beams of variable inertia and box-girders over the bridge

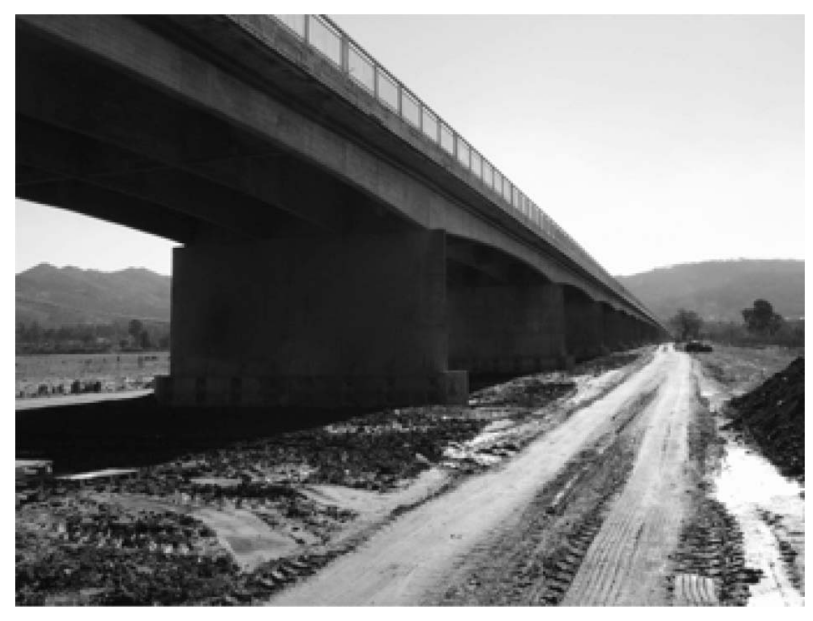

Figure 4. Lanheses Bridge.

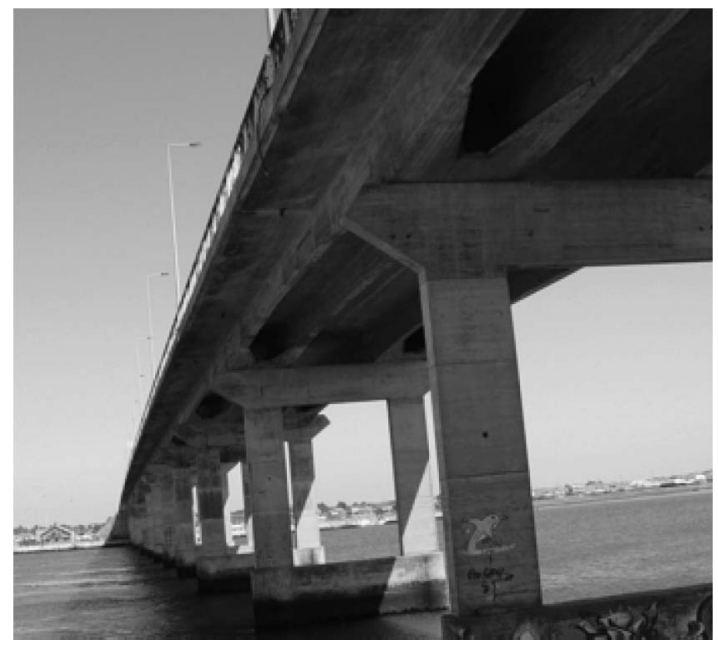

Figure 5. Barra Bridge. 
supports. These beams are prestressed longitudinally, are connected at the top face by the deck slab, and are connected transversally by reinforced concrete beams located over the support columns. The distance between columns is $32.0 \mathrm{~m}$, with the exception of the approach spans, which have a length of $25.0 \mathrm{~m}$. The columns, in reinforced concrete, possess a large slenderness and a rectangular cross-section. They are connected through transversal beams at the top and at the base, in the foundations. The transversal beams are connected to the longitudinal beams by neoprene supports. Finally, the abutments are walls in harmonium and extend for $20.9 \mathrm{~m}$.

\subsection{Bridge over the River Ave}

The bridge over the River Ave is located close to Guimarães, in Portugal, at the A11 highway. The various aspects of the bridge have been illustrated by Cruz and Wisniewski (2004). The bridge consists

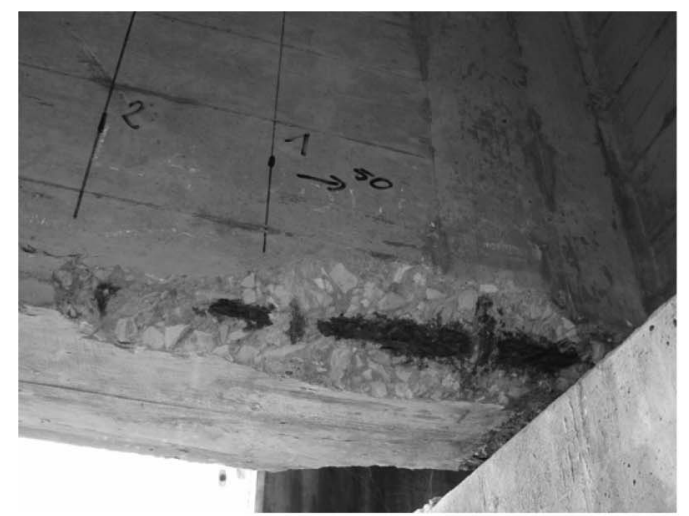

(a) mainly of three parts: two access viaducts characterised by a continuous bridge deck supported by circular columns, and a central rigid frame consisting of a prestressed bridge deck supported by boxgirders, with V-leg piers at the extremities of the single span.

\section{Application to detect tendon ducts and ordinary reinforcement}

The rehabilitation and structural strengthening currently being carried out in the Barra and Lanheses Bridges include the addition of external strengthening through longitudinal external prestressed cables and transverse prestressed threaded iron bars on the bridge supports. The strengthening devices will be fixed through steel devices, directly tied up to the longitudinal beams.

As soon as the work began, designers noticed that the tendon ducts were not located in the positions

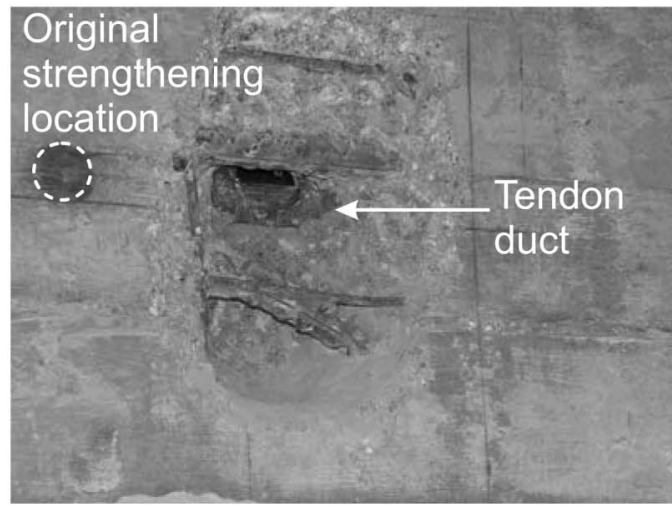

(b)

Figure 6. Example of: (a) corrosion of the reinforcement in the Barra Bridge, and (b) window opened in a longitudinal beam for the detection of tendon ducts in the Lanheses Bridge.

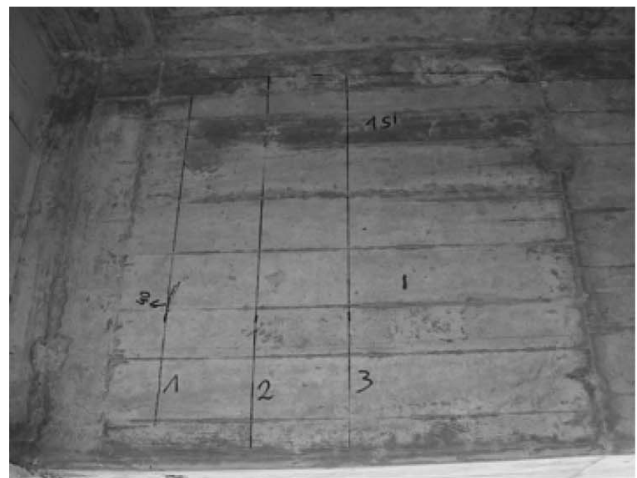

(a)

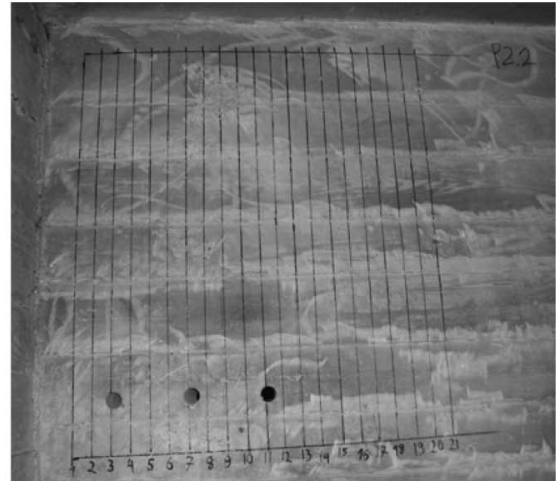

(b)

Figure 7. Examples of measuring vertical and horizontal lines in beams at: (a) Barra Bridge with a line separation of $20 \mathrm{~cm}$, and (b) Lanheses Bridge with a line separation of $5 \mathrm{~cm}$. 
defined in the original design plans. Without this information, a real risk of damaging the prestressed cables existed. Thus, it was fundamental to assess the exact position of the ordinary reinforcement and the tendon ducts in several specific locations. Figure 6 illustrates examples of some damage and the consequences of semi-destructive techniques typically employed to locate essential structural elements such as tendon ducts. In fact, in this particular bridge, the holes for the external strengthening were drilled without prior knowledge or true assessment of the real position of the tendon ducts. Figure $6 \mathrm{~b}$ shows that the initial design position of the strengthening elements would have caused damage to the existing tendon ducts.

The detection of the metallic elements was carried out with a commercial GPR system from MALA Geoscience. The field acquisitions mostly consist of 2D radargrams carried out in the longitudinal beams of the two bridges with the objective of detecting the ordinary reinforcement and the steel tendon ducts in the inspected area. The antenna used for these surveys was a $1.6 \mathrm{GHz}$ high-frequency antenna. The area of interest consists of panels of $2 \times 1 \mathrm{~m}$ or $1 \times 1 \mathrm{~m}$. In each position a set of parallel and vertical lines was defined to perform accurate GPR acquisitions (see Figure 7). The distance between consecutive lines was $20 \mathrm{~cm}$, and, in some cases, $5 \mathrm{~cm}$ (used for subsequent $3 \mathrm{D}$ processing). In general, the average speed of propagation of the electromagnetic wave was to be around $10.2 \mathrm{~cm} / \mathrm{ns}$, which was determined by calculating the time needed by the electromagnetic pulse to travel from the antenna towards a metallic shield that was located on the opposite side of the beam.

\subsection{Lanheses Bridge}

In the Lanheses Bridge, all the radar acquisitions were performed over support columns. As such, the examples shown refer to two of these test locations. The first example was acquired on a beam in the middle of the width of the bridge deck and was acquired in both sides of a transversal beam. The area of interest consists of two $1 \times 1 \mathrm{~m}$ panels, with vertical profiles distanced by $20 \mathrm{~cm}$. Figure 8 illustrates the procedure for the general interpretation of the

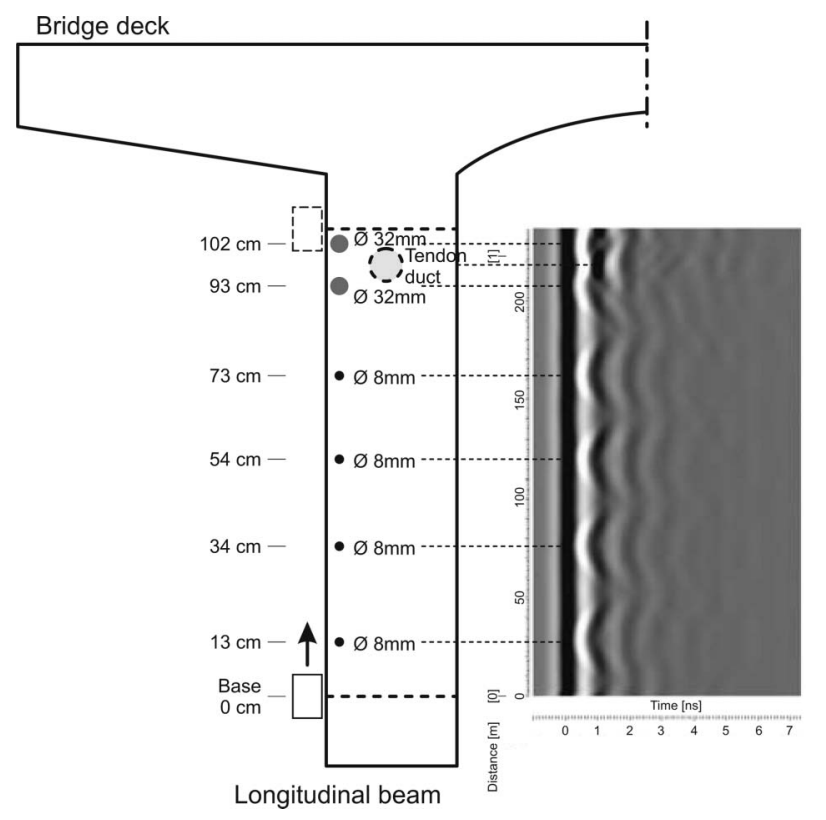

Figure 8. Schematic exhibiting the interpretation of a common 2D radargram.

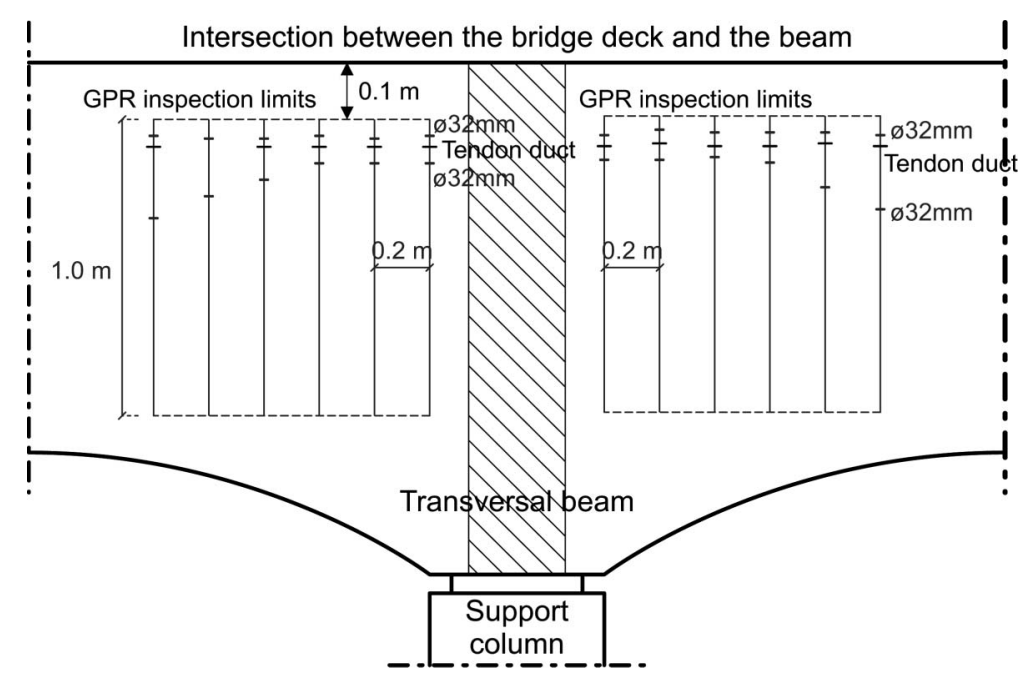

Figure 9. Graphical representation of the detected reinforcement and tendon ducts from one of the two internal-external beams. The presence of the transversal beam prevented the continuous acquisition of data. 


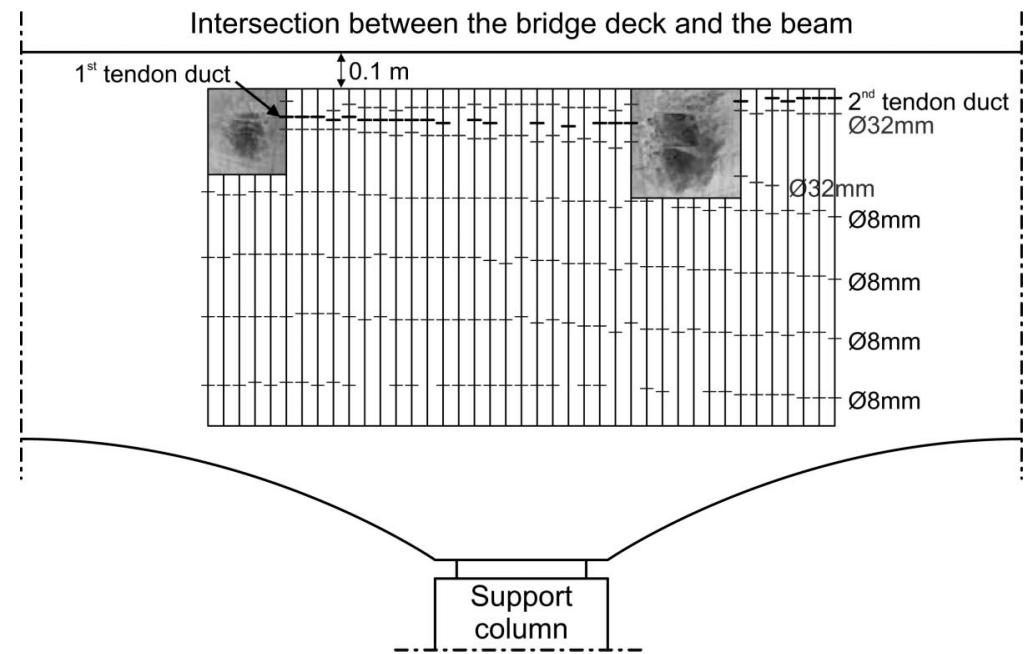

Figure 10. Graphical representation of the reinforcement and tendon ducts from the external beam. The data was obtained from $2 \mathrm{D}$ radargrams and from the $3 \mathrm{D}$ volume.

GPR radargrams, where the characteristic signals from the detection of linear objects such as bars and tendon ducts can be observed.

The results illustrated in Figure 9 depict the positions of the steel reinforcement bars of $\varnothing 32 \mathrm{~mm}$ and the tendon duct. Thus, it is possible to predict, with sufficient accuracy, the path of the tendon duct and the main reinforcement bars to plan the location of the strengthening, without harming the existing structural elements.

A second example was located in the external surface of a beam located in the extremity of the bridge. At this position, two small windows were opened to verify the real location of the tendon ducts. As a result, it was not possible to carry out continuous acquisition, and the area was split into four smaller areas. The distance between the profiles was $5 \mathrm{~cm}$, which allowed sufficiently accurate data to be obtained for $3 \mathrm{D}$ subsequent processing.

The elements detected were four reinforced bars of $\varnothing 8 \mathrm{~mm}$ spreading along the entire length investigated with GPR and separated by $20 \mathrm{~mm}$, which is corroborated by the original design plans, two reinforced bars of $\varnothing 32 \mathrm{~mm}$ at the top of the beam and the presence of two tendon ducts. Figure 10 illustrates the position of the ordinary reinforcement and the prestressed cables in the tendon ducts. It must be noted that the lower tendon duct was not detected in the right superior corner due to difficulties related to steel concentration above the tendon.

These results were further processed in 3D with the objective of improving the interpretation of the previous results and assess the usefulness of 3D

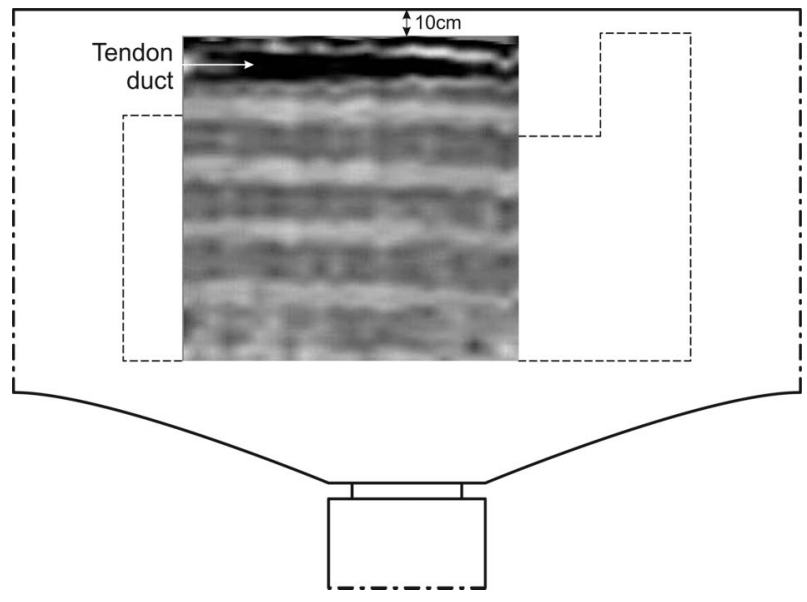

Figure 11. Example of a depth slice taken from the main $3 \mathrm{D}$ volume with the indication of the tendon duct between the $\varnothing 32 \mathrm{~mm}$ steel bars, at $15 \mathrm{~cm}$ depth.

reconstruction for these tasks. See Fernandes (2006) for further details on 3D reconstruction techniques. Partial results for the tested area are shown in Figure 11, which illustrates one depth slice from the 3D volume, at about $15 \mathrm{~cm}$ of depth, which shows the tendon duct located between the $\varnothing 32 \mathrm{~mm}$ bars at the top of the beam. Another one, at about $5 \mathrm{~cm}$ of depth, shows the disposition of the $\varnothing 8 \mathrm{~mm}$ and $\varnothing 32 \mathrm{~mm}$ reinforcement (not illustrated). The 3D volume also reveals the presence of vertical reinforcement at some points, although its identification is not accurate due to the fact that the methodology used in this case was not favourable for the detection 
of such bars; the acquisition of additional horizontal profiles in the same area is necessary for this purpose.

\subsection{Barra Bridge}

For this bridge, GPR acquisitions were carried out at 21 locations. Of these positions, 13 were accessible through a fixed platform under the access viaducts of the bridge, while the remaining positions were located over the water and, thus, were only accessible with a mobile platform. Figure 12 illustrates examples of both situations.

In each position, two to five vertical lines were carried out according to the accessibility, the surface's nature and the geometrical characteristics of the testing area. The vertical lines were executed with the maximum possible length (between 1 and $1.5 \mathrm{~m}$ ). However, there were cases where it was not possible to reach the entire height of the longitudinal beam, especially when access was made through the mobile platform. Thus, in order to have a reference point that would allow the correct introduction of the location of the tendon ducts during design, the acquisition has always stopped at $10 \mathrm{~cm}$ from the edge between the bridge deck and the longitudinal beam.

It must be noted that the different smoothness of the surface significantly influenced the field acquisitions and conditioned the normal working of the antennas. Generally, the surfaces of the beams were rough and exhibited sharp edges of concrete in the surface due to the type of formwork used in the construction period. Thus, in the cases where the surface was not in adequate condition for test execution, and if concrete drips and roughness were detected, preliminary cleaning and levelling were usually carried out.

Due to the large number of test sites and the vast amount of data, only two examples located in places that were characteristic of the bridge will be presented here. These are located in the first span of the bridge erected over solid ground. Figures 13 and 14 respectively illustrate examples of the localisation of the tendon ducts at the mid-span between supports and over a support column. The results are presented in

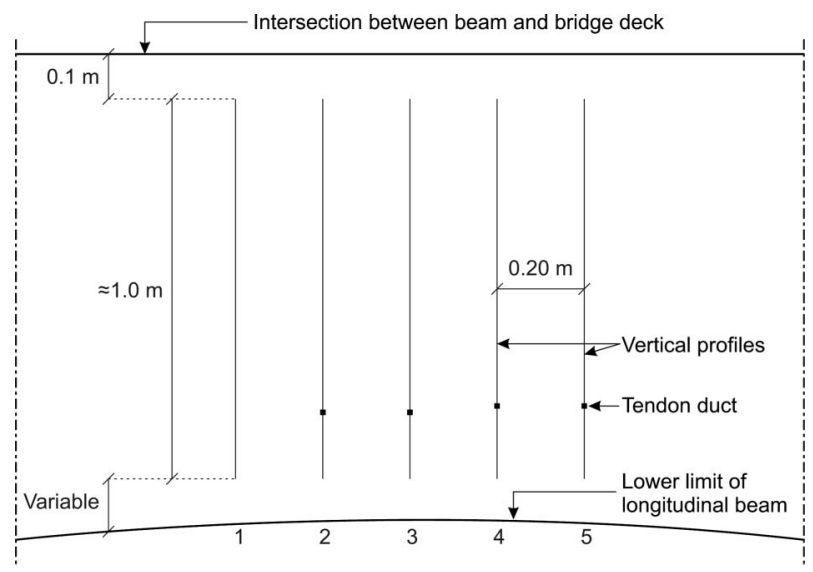

Figure 13. Location of the tendon duct in a position that corresponds to a cross-section at the mid-span of the beam.

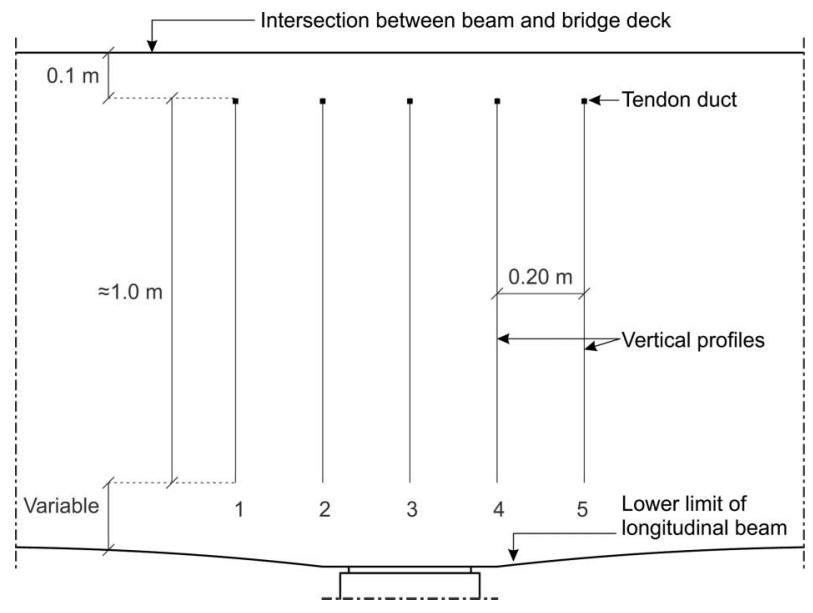

Figure 14. Location of the tendon duct in a position that corresponds to a cross-section over a support column.

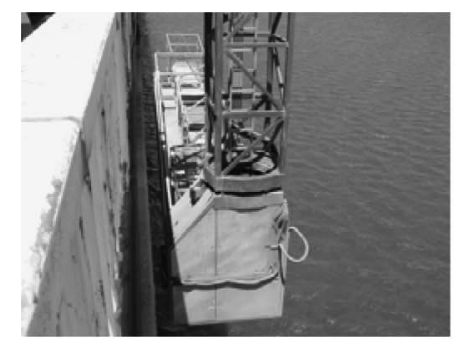

(a)

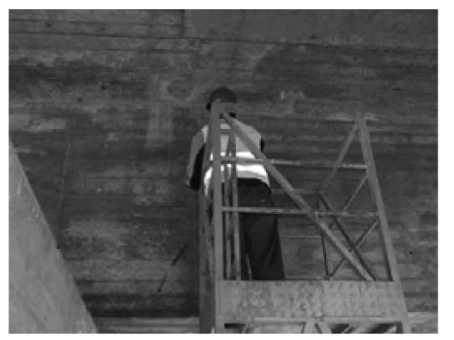

(b)

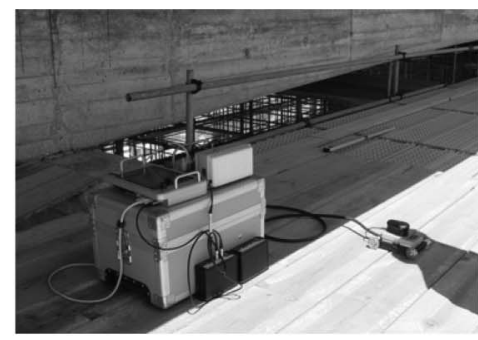

(c)

Figure 12. Example of method for accessing test sites: (a), (b) from an articulated mobile platform, and (c) over a continuous scaffolding system. 


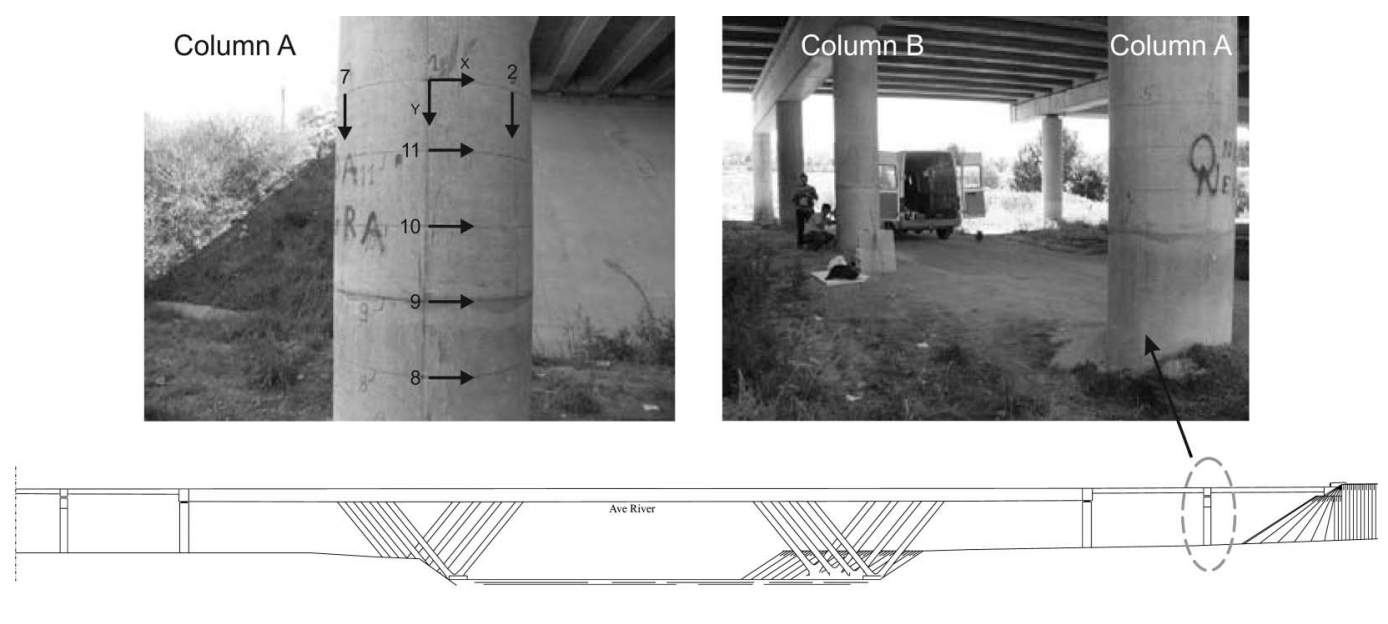

(a)

(b)

Figure 15. View of: (a) column A, and (b) the two columns tested. Also shown are the coordinate system used and the alignment of the horizontal and some of the vertical profiles.

such a way that, for each vertical radar profile, the location of the tendon duct is carried out through a small and thick horizontal line. As expected, the tendon ducts are localised in the bottom of the beam, when the radar acquisition is carried out in the midspan of the beam. The tendon ducts are localised in the top of the same beams when the radar acquisition is performed directly over a support column.

\section{Application to construction and concrete quality control}

During the construction of the concrete bridge over the Ave River, a significant number of different sensors were installed to monitor corrosion, humidity, temperature, etc. (Cruz and Wisniewski 2004). Shortly after the end of the construction, some of the corrosion sensors indicated large corrosion values in some structural elements. The largest values were located in two of the columns in the access viaduct and inside one of the box-girders supporting the bridge deck. In order to assess the possible deterioration inside the elements that exhibit corrosion, a GPR survey was carried out in two circular columns on the access viaducts. Two different pieces of equipment were used, one from MALA Geoscience with one $1.6 \mathrm{GHz}$ antenna for reflection measurements, and a second one from Geophysical Survey Systems, Inc. with two $900 \mathrm{MHz}$ antennas for transmission measurements.

Two columns were then chosen. In the first column (A), the embedded sensor did not indicate any signs of corrosion. In a second column (B), the sensor indicated the occurrence of corrosion in the metallic reinforcement.

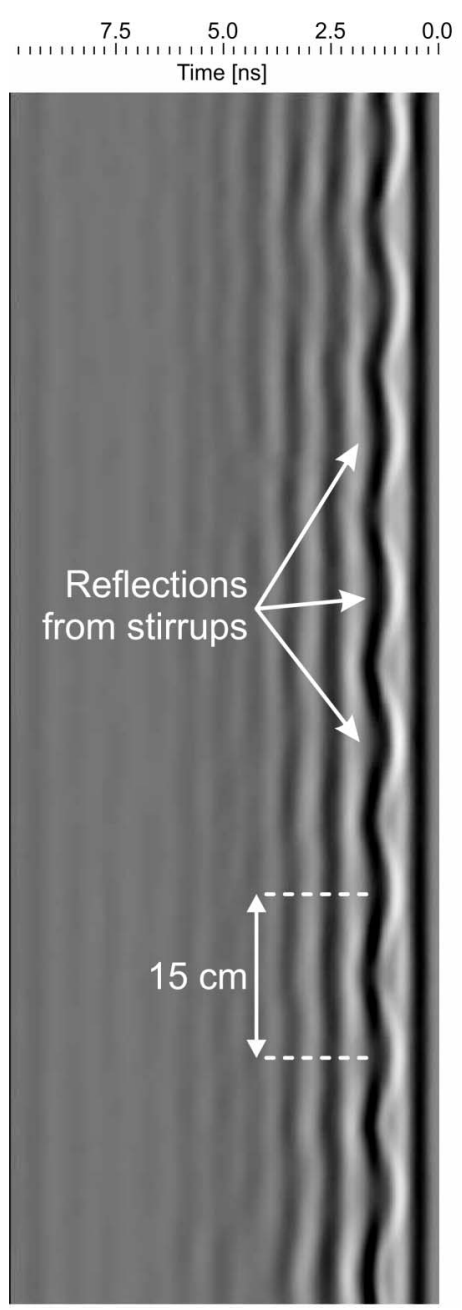

Figure 16. Example of one radargram from vertical lines with marked reflections from the stirrups (column A). 


\subsection{Intact column-column $A$}

The location of the test object is illustrated in Figure 15. The measurements were carried out with the $1.6 \mathrm{GHz}$ antenna in reflection mode around the entire circumference of the column, in the location of the corrosion sensor. These measurements resulted in the following profiles: seven vertical profiles carried out from top to bottom, $1.2 \mathrm{~m}$ in length and performed every $45 \mathrm{~cm}$; and five horizontal profiles carried out from left to right, $3.15 \mathrm{~m}$ in length and performed every $40 \mathrm{~cm}$.

The vertical profiles basically show the presence and frequency of stirrups (secondary reinforcement).

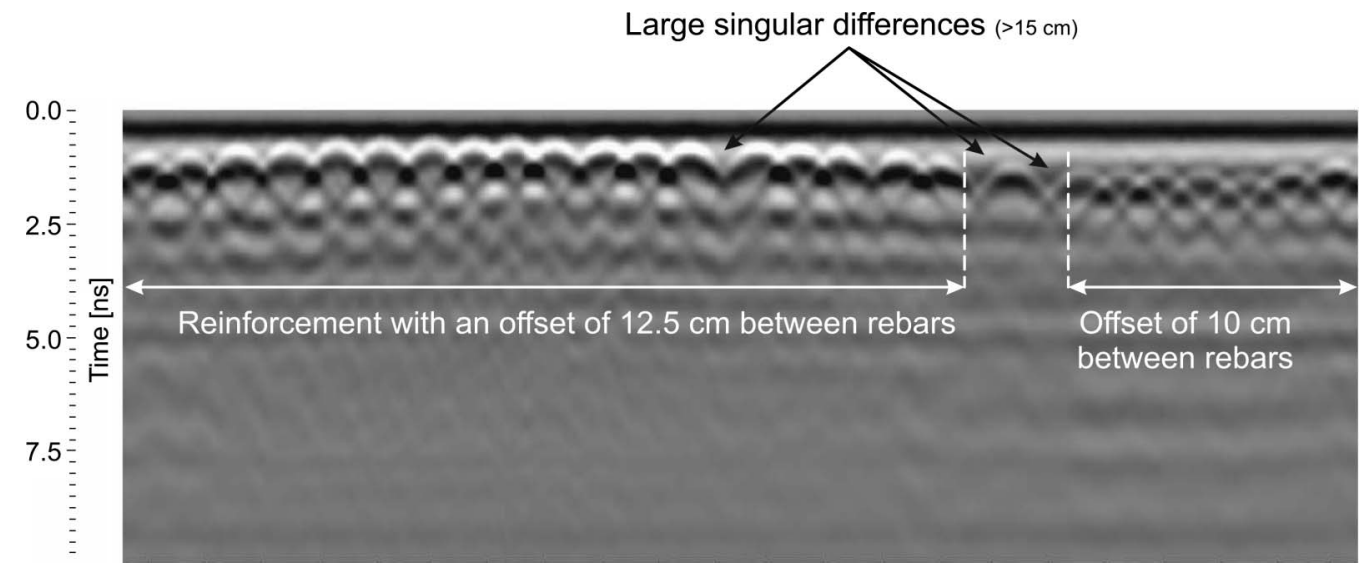

Figure 17. Radargram showing different offsets between rebars.

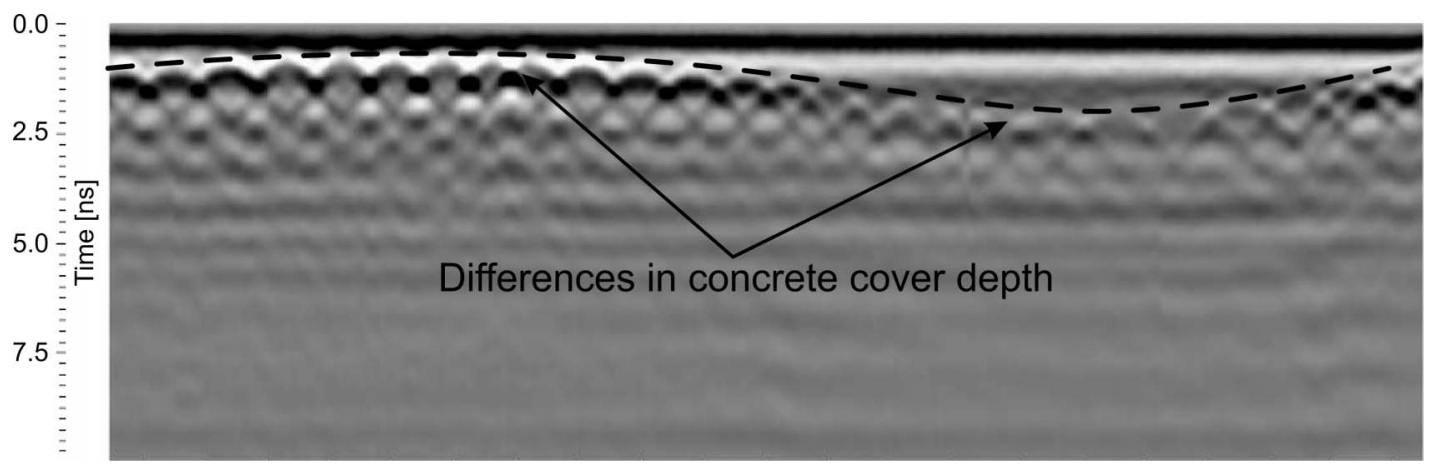

Figure 18. Radargram from a horizontal profile of column B showing large differences in the cover layer of reinforcement.

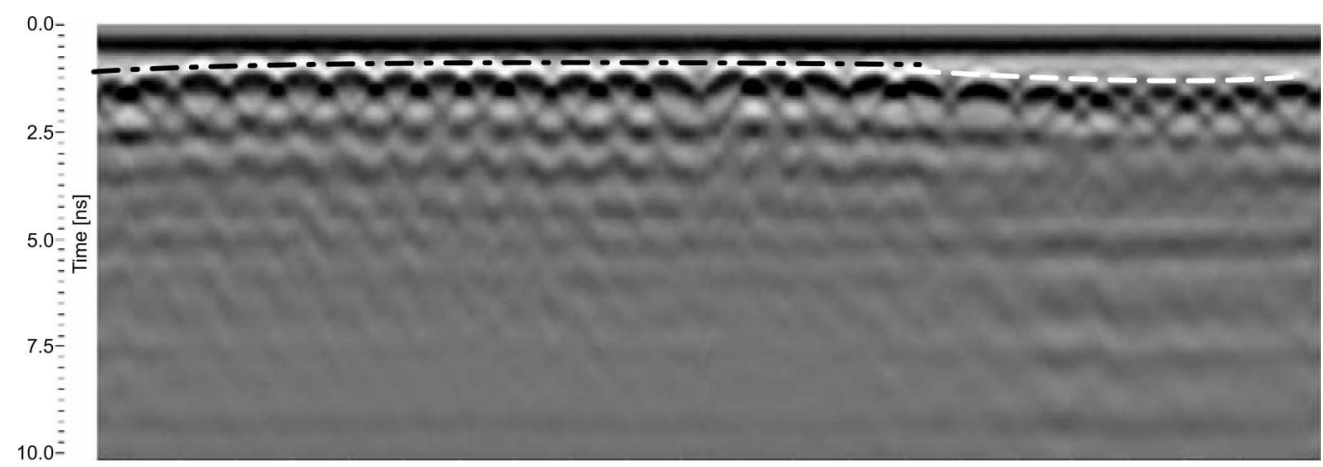

Figure 19. Radargram located at the top of the area investigated in column B showing the smallest differences in the cover layer of reinforcement. 
According to the design drawings, these stirrups should be placed every $15 \mathrm{~cm}$. Typical radargrams, such as the one illustrated in Figure 16, show that the secondary reinforcement was placed correctly.

The horizontal profiles were acquired from the same starting point and following the same direction as the vertical ones, as illustrated in Figure 15. Generally, two main situations occurred in all the profiles acquired. Firstly, the distance between reinforcing bars is not constant along the circumference of the column. Figure 17 shows a radargram where differences of the distance between bars can be observed. These distances range from 10 to $12.5 \mathrm{~cm}$, although larger differences are observed at three singular points. Secondly, the concrete cover changes along the circumference of the column. Apparently, a difference of time of around $0.5 \mathrm{~ns}$ is observed in most radargrams, which means a difference of approximately 2.5 to $3 \mathrm{~cm}$ in depth. This difference means that some of the reinforcement bars are located very close to the surface, which can cause an early occurrence of corrosion.

\subsection{Column with corrosion activity - column B}

For column B, measurements and processing steps were identical to those carried out in column $\mathrm{A}$ and follow the same rules as in Figure 15. This column was chosen because the embedded sensor (sensor C41) indicated the occurrence of corrosion.

The vertical profiles show the location of the secondary reinforcement and the results showed that this reinforcement was placed correctly, as in the case of the column A. Regarding the horizontal profiles, it can be observed that in the bottom part of the column there is a significant deficiency in the positioning of the main reinforcement, which shows a tendency to deviate towards the centre of the column. This phenomenon is well illustrated in Figure 18, which shows a profile located below the construction joint, where a difference of up to $8 \mathrm{~cm}$ between the different cover depths is detected.

On other profiles, this shift progressively reduces. In the profile illustrated in Figure 19, there is almost no deviation of the main reinforcement towards the centre of the column, which suggests that in the part of the column above the construction joint, the construction's quality is higher. The distance between primary reinforcements is around $12.5 \mathrm{~cm}$, matching the original design drawings. Figure 20 shows a sketch of the probable real position of the main reinforcement, and illustrates how the main reinforcement is possibly distributed along the column.

This situation requires further investigation of the entire columns, and also of the remaining columns, in order to assess the real position of the steel bars, as it can affect the resistance and durability of the columns.

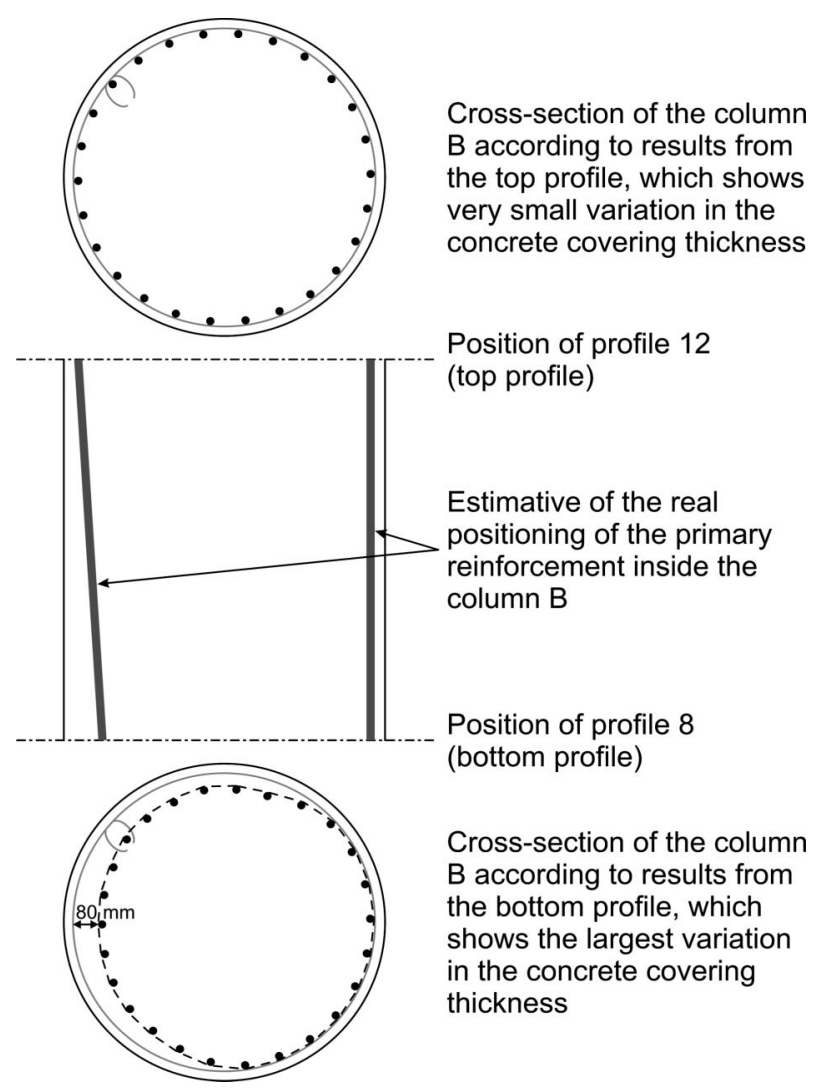

Figure 20. Design drawing of the column indicating: the real position of the main reinforcement (top) with respect to the original design (bottom). A deviation of up to $8 \mathrm{~cm}$ is found. Correct position of the primary reinforcement (estimation) along the tested length.

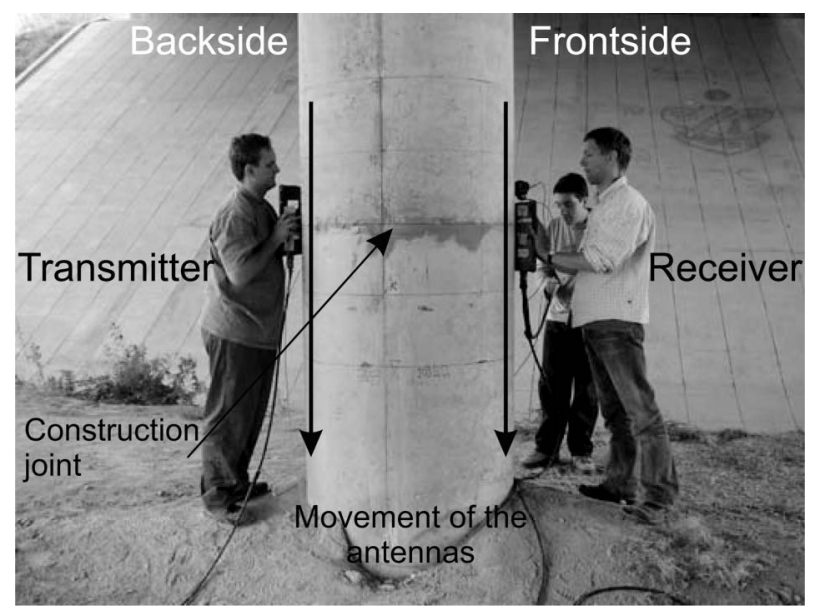

Figure 21. Acquisition of the transmission measurement with transmitter and receiver antennas at opposite sides of column B. Positions of the transmitter antenna and profile length of $1.2 \mathrm{~m}$ of the receiver at column $\mathrm{B}$. 


\subsection{Transmission measurements in column $B$}

Transmission measurements were additionally performed around the construction joint. Due to the fact that this is a time consuming methodology, this technique was only applied to column $\mathrm{B}$, where the corrosion sensor indicated the occurrence of a very large value of current resistance, which indicated that the steel was severely corroded. The objective was to detect deteriorated areas that could explain the high values. Due to a lack of sufficient penetration of the 1.6 GHz antenna, the $900 \mathrm{MHz}$ antennas were used instead. The main acquisition mode is illustrated in Figure 21.

The measurements were carried out with the antennas in the vertical position. At each position, each $5 \mathrm{~cm}$, the transmitter antenna was fixed, while the receiver was moved along the entire length, from top to bottom, which resulted in 25 profiles of $120 \mathrm{~cm}$ in length. For error checking purposes, a second identical measurement was performed whilst changing the position of the transmitter and receiver antennas.

The data processing was carried out in various steps. Firstly, the length of the various profiles was adjusted and the data input prepared and properly checked. Then, the data was introduced into the inversion program and various tomograms were obtained, representing a map with the distribution of the velocity of the electromagnetic waves along the cross-sectional area tested. In this case, velocity maps such as those illustrated in Figures 22 and 23 were obtained.

The entire dataset of profiles was used to produce the velocity tomogram illustrated in Figure 22. From this tomogram, it is possible to observe that the column can be divided in two regions, above and below the construction joint, which exhibit different velocities. The concrete above the construction joint presents a higher velocity with respect to the concrete below the joint (10\% larger on average). This result strongly suggests that the concretes used in this column are different. Generally, areas of higher velocity values indicate the presence of concrete deterioration, which can be caused by an effect of the corrosion or by poor compaction during the construction phase.

However, a significant number of artefacts (which can be defined as false, multiple or misleading information introduced by the imaging system or by the interaction of the electromagnetic waves with the

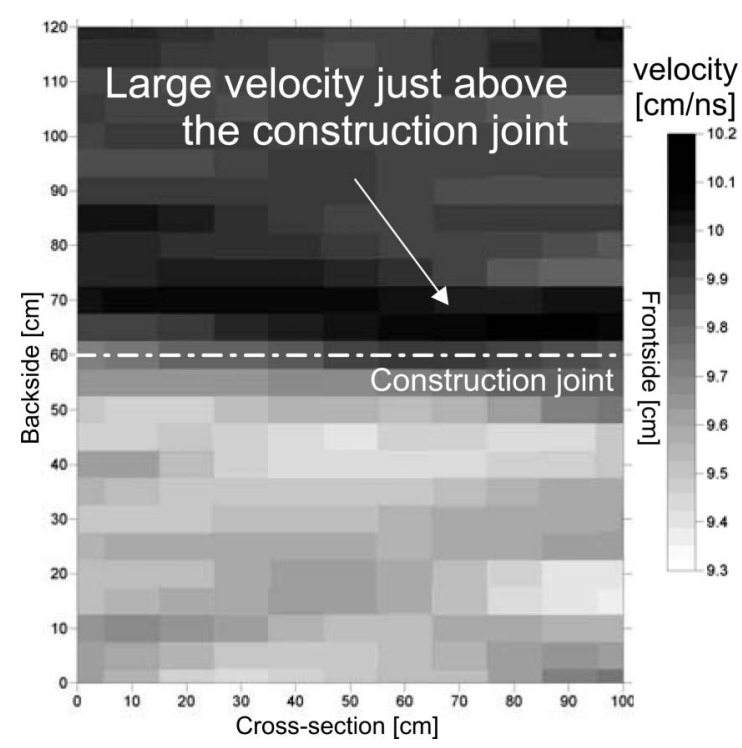

Figure 23. Velocity tomogram showing the velocity distribution in the cross-section of column B. This tomogram was produced with the profiles that had a ray inclination between $\pm 20^{\circ}$ and represent the final tomogram.

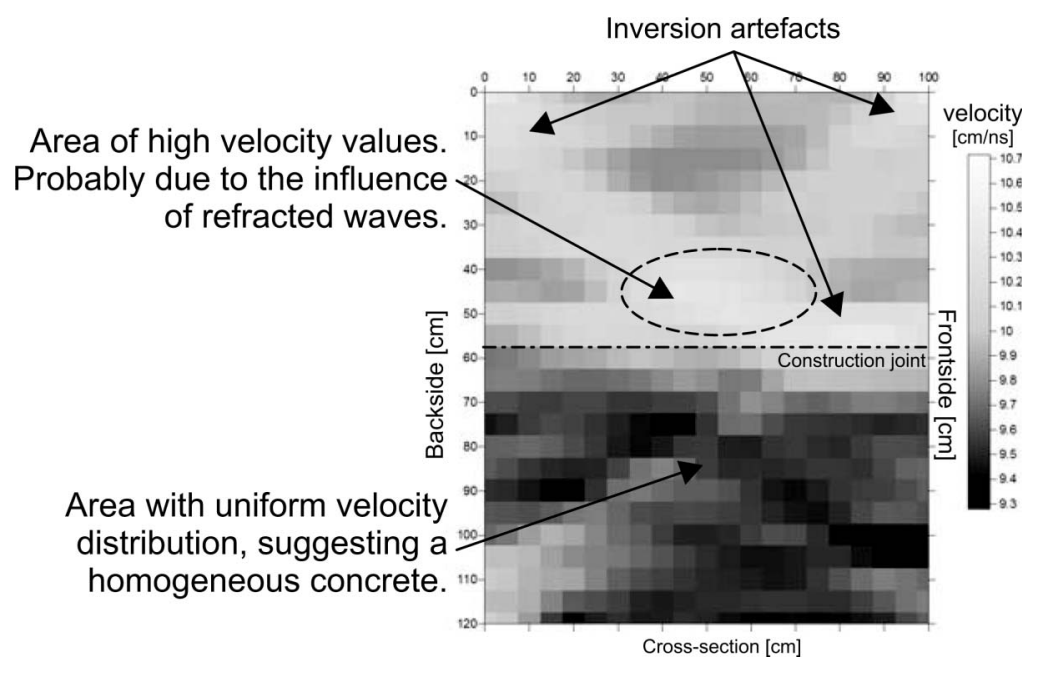

Figure 22. Velocity tomogram showing the velocity distribution in the cross-section of column B. 
adjacent materials) and the presence of refraction effects in the travel time data resulted in a rather poor quality tomogram. To overcome this situation, new velocity tomograms were produced, with the profiles where the transmitter-receiver angle was between $\pm 20^{\circ}$. The result of this new tomogram is illustrated in Figure 23. Just above the joint, a noticeable change of the velocity is confirmed, which can indicate the presence of very poorly vibrated concrete or deterioration in the column at the level of the construction joint. Due to the different time periods of construction, the most probable explanation is that the concrete above the construction joint shows the result of insufficient vibration.

\section{Conclusions}

GPR is a fast and reliable technique to inspect concrete structures, and it has been used recently to inspect bridges to locate deterioration and nonvisible information such as tendon ducts and the true location of reinforcement. This paper focused on three case studies in major bridges in Portugal and clearly illustrated the potential of the NDT technique, when combined with powerful signal processing tools.

The first two case studies address bridge inspection, and a standard GPR system with high-frequency antennas allowed the position of the tendon ducts, which is a fundamental element for the safety of bridges, to be accurately detected. The inspection concluded that the tendon ducts were, in some cases, shifted with respect to the original design location. This information is important for efficient structural assessment and strengthening design. First, the information allows the real contribution of existing structural elements in the numerical and analytical models for strengthening design to be taken into account. Secondly, by determining the true position of tendon ducts and, more importantly, steel bars, the strengthening with external prestressing can be better planned and damage of the existing elements can be avoided during rehabilitation work. It must be noted that, with the results of this work, the engineers responsible for the strengthening design were able to change the previous design in order to avoid drilling in locations where this would cross through existing tendon ducts.

In the last case study, GPR was used for the early detection of material and construction defects. The early detection of defects can help to adopt corrective measures (if necessary) to prevent further damage and to understand early occurrence of deterioration. The inspection of the support columns in a recent highway concrete bridge, which seems to register the occurrence of high levels of corrosion, allowed the detection of deficiently positioned steel bars. Some of those bars were located very close to the surface, favouring the early occurrence of corrosion, while other bars where positioned deeper towards the centre of the column, affecting the design stresses, which can cause cracking and deformation of those structural members. Additionally, the application of advanced GPR tomography allowed the quality of the concrete to characterised, indicating the presence of execution defects.

\section{Acknowledgements}

L.T. would like to acknowledge the support from the 'Sustainable Bridges' European project, grant number FP6PLT-01653 (www.sustainablebridges.net). F.M.F. acknowledges the partial funding of this work by the FCT through the scholarship POCTI SFRH/BPD/26706/2005.

\section{References}

Becht, A., Tronicke, J., Appel, E., and Dietrich, P., 2004. Inversion strategy in crosshole radar tomography using information of data subsets. Geophysics, 69 (1), 222-230.

Binda, L., Saisi, A., Tiraboschi, C., Valle, S., Colla, C., and Forde, M.C., 2003. Application of sonic and radar tests on the piers and walls of the Cathedral of Noto. Construction and Building Materials, 17 (8), 613-627.

Buyukozturk, O., 1998. Imaging of concrete structures. NDT\&E International, 31 (4), 233-243.

Cruz, P.S.J. and Wisniewski, D.F., 2004. Ave River Bridge a major precast prestressed U-girder bridge in Portugal. PCI Journal, July-August issue, 72-85.

Daniels, D.J., 2004. Ground penetrating radar. 2nd ed. Radar, sonar, navigation and avionics series 15 . London, UK: IEE.

Dérobert, X., Aubagnac, C., and Abraham, O., 2002. Comparison of NDT techniques on a post-tensioned beam before its autopsy. NDT\&E International, 35 (8), 541-548.

Fernandes, F.M., 2006. Evaluation of two novel NDT techniques: microdrilling of clay bricks and ground penetrating radar in masonry. Thesis (PhD). University of Minho. Available from: http://www.civil.uminho.pt/masonry.

Forde, M.C., 2004. Ground penetrating radar. In: Introduction to non-destructive evaluation technologies for Bridges Conference. Transportation Research Board, $83^{\text {rd }}$ Annual Meeting, Washington DC, USA.

Giannopoulos, A., Macintyre, P., Rodgers, S., and Forde, M.C., 2002. GPR detection of voids in posttensioned concrete bridge beams. In: 9th international conference on ground penetrating radar, Santa Barbara USA, CA, 376-381.

Hugenschmidt, J., 2002. Concrete bridge inspection with a mobile GPR system. Construction and Building Materials, 16 (3), 147-154.

Maierhofer, Ch. and Kind, Th., 2002. Application of impulse radar for non-destructive investigation of concrete structures. In: 9th international conference on ground penetrating radar, Santa Barbara, USA, CA, 382-387. 
Maierhofer, Ch., Brink, A., Röllig, M., and Wiggenhauser, H., 2003. Detection of shallow voids in concrete structures with impulse thermography and radar. $N D T \& E$ International, 36 (4), 257-263.

Mitchell, T.M., 2004. Radioactive/nuclear methods. In: V.M. Malhotra and N.J. Carino, eds. CRC handbook on nondestructive testing of concrete. 2nd ed. Florida: CRC Press.

Olson, L.D., 2004. Stress wave NDE methods for condition assessment of the superstructure and substructure of concrete bridges. In: Transportation Research Board, Preconference workshop, Introduction to nondestructive evaluation technologies for bridges, $83^{\text {rd }}$ Annual Meeting, Washington DC, USA.

Scott, M., Rezaizadeh, A., Delahaza, A., Santos, C.G., Moore, M., Graybeal, B., and Washer, G., 2003. A comparison of nondestructive evaluation methods for bridge deck assessment. NDT\&E International, 36 (4), 245-255.

Taffe, A., Borchardt, K., and Wiggenhauser, H., 2003. A specimen for the improvement of NDT methods, design and construction of a large concrete slab for NDT methods at BAM. In: International symposium on nondestructive testing in civil engineering (NDT-CE). Berlin, Germany: CD-ROM.
Topczewski, L., Fernandes, F., Cruz, P.J.S., Lourenço, P.B., and Ramos, L., 2006. Radar investigation on civil structures using 3D data reconstruction and transmission tomography. In: Structural faults and repair conference. Edinburgh, UK: CD-ROM.

Tronicke, J., Dietrich, P., and Appel, E., 2002. Quality improvement of crosshole georadar tomography: preand post-inversion data analysis strategies. European Journal of Environmental and Engineering Geophysics, 7, 59-73.

Valle, S., Zanzi, L., and Lenzi, G., 2000. 2D and 3D focusing of ground penetrating radar data for NDT. In: 8th international conference on ground penetrating radar, Gold Coast, Australia, 157-162.

Valle, S., Zanzi, L., and Rocca, F., 1999. Radar tomography for NDT: comparison of techniques. Journal of Applied Geophysics, 41 (2-3), 259-269. 